\title{
Survival Outcome in Men with Prostate Cancer in Yazd Province, Central Iran, from 2001 to 2012
}

\section{Hassan-Ali Vahedian-Ardakani ${ }^{1}$, Mansour Moghimi ${ }^{2}$, Mohammad Shayestehpour ${ }^{3}$, Masoud Doosti ${ }^{4}$, Fahimeh Salari Shahrbabaki ${ }^{5}$}

${ }^{1}$ Department of Internal Medicine, School of Medicine, Shahid Sadoughi University of Medical Sciences, Yazd, Iran. ${ }^{2}$ Department of Pathology, School of Medicine, Shahid Sadoughi University of Medical Sciences, Yazd, Iran. ${ }^{3}$ Department of Virology, School of Public Health, Tehran University of Medical Sciences, Tehran, Iran. Infectious and Tropical Diseases Research Center, Shahid Sadoughi University of Medical Sciences, Yazd, Iran. ${ }^{5}$ Aliebn- Abitaleb School of Medicine, Islamic Azad University, Yazd Branch, Yazd, Iran.

\begin{abstract}
Background: Prostate cancer is the second-leading cause of cancer death among men in the world. This cancer has increased significantly during recent years in Iran and is the sixth most common malignancy in Iranian men. Survival rates for prostate cancer in Iran are unknown. The present study aimed to estimate survival of patients suffering from prostate cancer in Yazd, Iran. Methods: In this retrospective cohort study, data were collected from 100 men with prostate cancer registered in Shohadaye Kargar and Shahid Sadoughy hospitals in Yazd during the period 2001-2012. The Kaplan-Meier method was used to estimate the survival over time and Cox regression analysis was performed to calculate the hazard ratios according to demographic and risk variables. Results: The mean age of all patients was 74.4 years. They had a mean survival time of $70.78 \pm 4.94$ month. The 1 -year, 3 -year, and 5 -year survival rates were $97 \%, 73 \%$, and $54 \%$, respectively. A statistically significant correlation was found between age, tumor grade, cancer stage, treatment and survival time of patients $(\mathrm{p}<0.05)$. The worst survival was in men with Gleason score 8-10 and stage IV of prostate cancer. Data showed no significant association between place of residence and patients' survival ( $p>0.05$ ). Conclusion: In this study, 5-year survival of patients with prostate cancer was poor. Screening of men for cancer diagnosis in early stages and use of advanced treatment option, it seems to improve survival outcome. Further studies are needed to monitor the survival of patients with prostate cancer in Iran.
\end{abstract}

Keywords: Prostate cancer- survival rate- Iran

Asian Pac J Cancer Biol, 2 (2), 23-26

\section{Introduction}

Prostate cancer is the second most common malignancy in men worldwide and the sixth common cancer in Iranian men [1]. This cancer affects over one million people and causes more than 300,000 death each year. In 2016, about 180,890 new cases and 26,120 prostate cancer-associated deaths were occurred in the United States [2]. Among the Asian countries, Israel, Turkey, Lebanon, Singapore and Japan have the highest incidence rate of prostate cancer. The number of new cases of prostate cancer in Iran has reported 10.7 per 100,000 people annually [1]. In Iran, the mortality rate of prostate cancer has increased during
Submission Date: 02/15/2017 Acceptance Date: 05/25/2017

the past two decades from 0.63 per 100, 000 population to $6[1,3]$.

Age, race, inheritance, diet, smoking, benign prostatic hypertrophy and hormones are possible risk factors for prostate cancer [4]. Incidence of prostate cancer increases with advancing age. More than $80 \%$ of prostate cancers are diagnosed in men aged 65 years and older. In Iran, over $95 \%$ of cases occur in the age group above 50 years old [5].

The survival of patients with prostate cancer is related to several factors, including the grade of tumor, patient's age and prostate-specific antigen (PSA) level [6]. Survival is significantly poorer in older patients with end-stage prostate cancer and PSA>100 ng/mL [7]. Socioeconomic

Corresponding Author:

Dr. Fahimeh Salari Shahrbabaki

Aliebn- Abitaleb School of Medicine, Islamic Azad University, Yazd Branch, Shohada-e-Gomnam Boulevard, Safaieeh, Yazd, Iran.

Email: h.vahedian@ssu.ac.ir 
status and treatment also have a significant influence on prostate cancer survival [8]. Survival of patients suffering from prostate cancer has improved dramatically during the past decade in many Asian countries [1]. Improvements in survival can be associated with several possible causes, including early detection by prostate-specific antigen (PSA) testing, increased diagnostic activity with aggressive biopsy policies, development of surgical and radio therapeutic method and access to hormone therapy [9].

Despite significant improvements in survival of patients with prostate cancer, however, geographical differences in survival exist, even between countries with similar healthcare [10]. Prostate cancer survival statistics can be useful for determining prognosis and evaluating treatment options. Therefore, knowing about cancer survival rates in any country and its different regions is necessary. Although the incidence of prostate cancer is increased in the last 10 years in Iran [5], the survival rate of Iranian patients is not clear. There are no published data on prostate cancer survival rates in Iran. Therefore, this study aimed to estimate the survival rate of patients with prostate cancer in Yazd province.

\section{Materials and Methods}

This retrospective cohort study was conducted on 100 patients with prostate cancer referred to Shohadaye Kargar and Shahid Rahnemon Hospitals in Yazd province, Iran between 2001 and 2011. All patients sign informed consent form to participate in the present study. Demographic characteristics of patients such as age, place of residence, type of treatment and telephone number were extracted from the medical records. Inclusion criterion was adult patients with confirmed prostate adenocarcinoma. Exclusion criteria were patients under 18 years old and adults with non-adenocarcinoma type of prostate cancer. Paraffin embedded tissues were independently reviewed by two pathologists to confirm the malignancy. Data were collected by a questionnaire and patient records. In addition, patients were followed-up via telephone to acquire and complete information regarding their current status. Variables included age, gender, grade and stage of cancer, place of residence and type of treatment. Data were analyzed using SPSS software version 21 (Chicago, IL, USA). Qualitative variables were demonstrated as proportions and continuous variables as mean $\pm \mathrm{SE}$. Kaplan-Meier analysis was used to estimate survival in patients with prostate cancer and differences in survival times were tested by log-rank test. A Multivariate analysis was performed using the Cox proportional hazard regression model. A p-value less than 0.05 was considered to be significant.

\section{Results}

In the present study, 100 patients with prostate cancer were followed up for survival analysis. Finally, 38 cases (38\%) were alive and 62 patients $(62 \%)$ died due to prostate malignancy. Detailed baseline characteristics of study participants are shown in Table 1. Patients were in age range of 54 to 95 years (mean: $74.4 \pm 8.5$ ). The mean and median survival time of patients with prostate cancer was $70.78 \pm 4.94$ (95\%CI: 61.09-80.47) and 62 months, respectively. The results of Kaplan Meir analysis are presented in Table 1. According to this data, age at the

Table 1. Survival Rates in Patients with Prostate Cancer According to Variables

\begin{tabular}{|c|c|c|c|c|c|c|c|c|}
\hline \multicolumn{3}{|c|}{ Variable } & $\begin{array}{c}\text { Number } \\
(\mathrm{c} /)\end{array}$ & \multicolumn{3}{|c|}{$\begin{array}{c}\text { Survival rate }(\%) \\
1 \text { year } 3 \text { year } 5 \text { year }\end{array}$} & $\begin{array}{l}\text { Mean survival time } \\
\pm \text { SE (month) } \\
92.84 \pm 7.56\end{array}$ & $P$ value \\
\hline Age (year) & $\begin{array}{l}54-74 \\
75-95 \\
\text { Total }\end{array}$ & & $\begin{array}{c}45(45) \\
55(55) \\
100(100)\end{array}$ & $\begin{array}{l}96 \\
98 \\
97\end{array}$ & $\begin{array}{l}85 \\
61 \\
73\end{array}$ & $\begin{array}{l}70 \\
38 \\
54\end{array}$ & $\begin{array}{l}92.84 \pm 7.56 \\
53.29 \pm 5.25 \\
70.78 \pm 4.94\end{array}$ & 0.0001 \\
\hline $\begin{array}{l}\text { place of resi- } \\
\text { dence }\end{array}$ & $\begin{array}{l}\text { Urban } \\
\text { Rural }\end{array}$ & & $\begin{array}{l}80(80) \\
20(20)\end{array}$ & $\begin{array}{l}94 \\
80\end{array}$ & $\begin{array}{l}77 \\
71\end{array}$ & $\begin{array}{l}55 \\
53\end{array}$ & $\begin{array}{c}71.89 \pm 5.66 \\
69.68 \pm 10.61\end{array}$ & 0.83 \\
\hline $\begin{array}{l}\text { Grade (Gleason } \\
\text { Score) }\end{array}$ & $\begin{array}{c}1-6 \\
7 \\
8-10 \\
\text { Unknown }\end{array}$ & & $\begin{array}{l}41(41) \\
16(16) \\
21(21) \\
22(22)\end{array}$ & $\begin{array}{l}98 \\
85 \\
82 \\
97\end{array}$ & $\begin{array}{l}90 \\
73 \\
62 \\
64\end{array}$ & $\begin{array}{l}73 \\
30 \\
18 \\
58\end{array}$ & $\begin{array}{c}100.38 \pm 7.97 \\
47.24 \pm 8.32 \\
38.79 \pm 5.38 \\
64.49 \pm 7.90\end{array}$ & $<0.05$ \\
\hline Stage & $\begin{array}{c}\text { I } \\
\text { II } \\
\text { III } \\
\text { IV } \\
\text { Unknown }\end{array}$ & & $\begin{array}{c}10(10) \\
13(13) \\
0 \\
25(25) \\
52(52)\end{array}$ & $\begin{array}{c}100 \\
100 \\
- \\
84 \\
87\end{array}$ & $\begin{array}{c}100 \\
100 \\
- \\
57 \\
72\end{array}$ & $\begin{array}{c}100 \\
90 \\
- \\
40 \\
38\end{array}$ & $\begin{array}{c}123.38 \pm 5.26 \\
112.15 \pm 9.56 \\
- \\
51.54 \pm 7.73 \\
54.78 \pm 4.80\end{array}$ & $<0.05$ \\
\hline & Radical prostatectomy & $\begin{array}{l}\text { Yes } \\
\text { No }\end{array}$ & $\begin{array}{c}7(7) \\
93(93)\end{array}$ & $\begin{array}{c}100 \\
83\end{array}$ & $\begin{array}{c}100 \\
72\end{array}$ & $\begin{array}{c}100 \\
46\end{array}$ & $\begin{array}{c}124 \pm 3.54 \\
66.99 \pm 4.98\end{array}$ & 0.018 \\
\hline Treatment & $\begin{array}{l}\text { Hormone therapy } \\
\text { Orchiectomy } \\
\text { No hormone therapy }\end{array}$ & & $\begin{array}{c}20(20) \\
73(73) \\
7(7)\end{array}$ & $\begin{array}{l}83 \\
93 \\
43\end{array}$ & $\begin{array}{l}60 \\
85 \\
28\end{array}$ & $\begin{array}{c}43 \\
58 \\
0\end{array}$ & $\begin{array}{c}55.13 \pm 9.16 \\
78.54 \pm 5.57 \\
21 \pm 6.40\end{array}$ & 0.0001 \\
\hline & Radiotherapy & $\begin{array}{l}\text { Yes } \\
\text { No }\end{array}$ & $\begin{array}{l}15(15) \\
85(85)\end{array}$ & $\begin{array}{l}66 \\
92\end{array}$ & $\begin{array}{l}42 \\
80\end{array}$ & $\begin{array}{l}25 \\
49\end{array}$ & $\begin{array}{l}42.87 \pm 8.79 \\
74.88 \pm 5.31\end{array}$ & 0.028 \\
\hline
\end{tabular}


Table 2. Results of Multivariate Survival Analysis Using Cox Regression Method

\begin{tabular}{|c|c|c|c|c|c|}
\hline \multicolumn{3}{|c|}{ Variable } & Hazard Ratio & $\begin{array}{c}\text { Confidence Interval } \\
(95 \%)\end{array}$ & P value \\
\hline Age (year) & \multicolumn{2}{|l|}{$\begin{array}{l}54-74 \\
75-95\end{array}$} & $\begin{array}{c}1 \\
1.852\end{array}$ & $\begin{array}{c}- \\
1.079-3.177\end{array}$ & $\begin{array}{c}\text { Ref } \\
0.025\end{array}$ \\
\hline Grade (Gleason score) & $\begin{array}{c}1-6 \\
7 \\
8-10 \\
\text { Unknown }\end{array}$ & & $\begin{array}{c}1 \\
2.746 \\
2.371 \\
2.130\end{array}$ & $\begin{array}{c}- \\
1.325-5.688 \\
1.169-4.809 \\
1.040-4.364\end{array}$ & $\begin{array}{l}\text { Ref } \\
0.007 \\
0.017 \\
0.039\end{array}$ \\
\hline Stage & $\begin{array}{c}\text { I } \\
\text { II } \\
\text { III } \\
\text { IV } \\
\text { Unknown }\end{array}$ & & $\begin{array}{c}1 \\
3.077 \\
- \\
7.600 \\
7.308\end{array}$ & $\begin{array}{c}- \\
0.019-0.997 \\
- \\
1.017-41.180 \\
1.003-32.804\end{array}$ & $\begin{array}{c}\text { Ref } \\
0.315 \\
- \\
0.048 \\
0.050\end{array}$ \\
\hline \multirow{3}{*}{ Treatment } & Radical prostatectomy & $\begin{array}{l}\text { No } \\
\text { Yes }\end{array}$ & $\begin{array}{c}1 \\
4.591\end{array}$ & - & $\begin{array}{c}\text { Ref } \\
0.131\end{array}$ \\
\hline & $\begin{array}{l}\text { No hormone the } \\
\text { Hormone ther } \\
\text { Orchiectom }\end{array}$ & & $\begin{array}{c}1 \\
0.758 \\
0.687\end{array}$ & $\begin{array}{c}- \\
0.288-1.995 \\
0.293-1.615\end{array}$ & $\begin{array}{c}\text { Ref } \\
0.575 \\
0.389\end{array}$ \\
\hline & Radiotherapy & $\begin{array}{l}\text { No } \\
\text { Yes }\end{array}$ & $\begin{array}{c}1 \\
0.73\end{array}$ & $\begin{array}{c}- \\
0.392-1.381\end{array}$ & $\begin{array}{l}\text { Ref } \\
0.34\end{array}$ \\
\hline
\end{tabular}

time of diagnosis was a significant predictor for survival in patients with prostate cancer $(\mathrm{p}=0.0001)$. Disease stages and grades had also significant effects on survival $(\mathrm{p}<0.05)$. Patients with prostate cancer stage I had the best survival while the worst outcome was seen in peoples suffering of prostate cancer stage IV. Radical prostatectomy and hormone therapy were increased survival rates in prostate cancer patients. Data obtained from comparing patients treated and untreated with radiotherapy indicated that radiation therapy is significantly decreased survival time in patients $(\mathrm{p}=0.028$, Table 1$)$.

Age, tumor grade, cancer stage and type of treatment were put in a multivariate Cox proportional hazard model to estimate HRs $(95 \% \mathrm{CI})$ and the results are summarized in Table 2. Age, tumor grade and cancer stage were significantly correlated with poorer survival. Older patients had higher risk of death. HR $(95 \% \mathrm{CI})$ for patients over 75 years of age was 1.85 (1.079-3.177) compared with the reference age group under 75 years. Stage IV prostate cancer was associated with a HR of 7.6 compared with stage I as the reference category (Table 2).

\section{Discussion}

This study was designed to estimate the survival of patients with prostate cancer in Yazd province of Iran. The medical records and histopathological findings of 100 prostate cancer patients were reviewed, and survival status for all participants was obtained via telephone interview. The effect of several factors, including age, place of resident, tumor grade, cancer stage, radical prostatectomy, hormone therapy and radiotherapy on the survival rate were investigated. Among these, only place of residence was not significantly affected on survival (Table 1). Studies in developing countries showed that patients with prostate cancer in rural and remote areas had poorer survival compared to urban residents [11-13].
In these countries, the use of diagnostic and treatment services among patients living in rural is lower than among their urban counterparts [14]. Our data was shown that Iranian urban and rural patients in Yazd province had similar survival rates; therefore, there is no difference concerning accessibility of medical facilities for residents of different regions.

Prostate cancer is considered an age-related malignancy because its incidence increases with age [5]. Our results are in compatible with previous reports that indicated survival time was inversely associated with patient age, and older peoples had a shorter survival compared with younger patients $[6,9]$. In the current study, $55 \%$ of cases were in the age group 75-95 years old with a 38\% survival rate at 5 years, whereas the five-year survival rate in younger patients (54-74 years) was $70 \%$. Lower prostate cancer survival time in older patients reflecting the role of other variables such as comorbidity, decreased immune response, and increased susceptibility to severe diseases [15].

In the present study, the data analysis revealed that the survival rates for patients with prostate cancer at the end of one, three and five years were $97 \%, 73 \%$, and 54\%, respectively (Table2). In Scotland, one-year and five-year overall survivals were $92 \%$ and $83 \%$, respectively [10]. According to the published data, the 5-year relative survival for patients suffered from prostate cancer was more than $85 \%$ in Australia, Japan, New Zealand, Singapore, South Korea, and 50-84\% in China and Thailand [16]. Overall five-year survival was reported $76.4 \%, 83.0 \%$ and $80.3 \%$ for England, Sweden and Norway, respectively [9]. Therefore, prostate cancer survival times are varied widely between countries due to socioeconomic status, cancer screening, and the early diagnosis of the malignancy using new medical facilities.

There are no published data on prostate cancer survival 
rates in Iran. In the only study conducted in the country, Taghipour Zahir etal. demonstrated that age and tumor grade can negatively affect survival of patients with prostate cancer in Iran [6]. However, they are not reported cancer survival rates. Similar to their results, we found that tumor grade and stage of disease were strong predictors of survival. The most common prostate cancer Gleason score in our study was lower than 7 (41\% of cases) that had a more favourable prognosis. Similar to other studies, patients with Gleason score 7 or greater had the worst survival rate. In addition, in compatible with previous reports, the present result revealed that the survival time of prostate cancer patients is related to cancer stage so that stage IV prostate cancer had a five-year survival rate of $40 \%$ (mean of survival time: 51 months). The 5-year survival rate for patients with stage IV prostate malignancy was $43 \%$ in Germany and 30\% in UK [17]. These findings indicate that the best strategy for increasing the survival of patents with prostate cancer is screening and detection of disease in early grades and stages.

In the present study, radical prostatectomy and hormone therapy could improve significantly survival in patients with prostate cancer. This finding is in consistent with those studies that found these treatment options for increasing the survival time in patients [18]. In our study, radiotherapy could not lead to improved survival may be because patients under treatment had an advanced cancer. However, several studies suggested that patient's survival was better after surgery compared to radiotherapy [19].

This study has several limitations, such as incomplete medical records, patients with unknown grade and stage of tumor, failure to refer patients for follow up and poor corporation of some patients during phone contact. Another limitation was the unavailability of information on comorbidity in cancer patients which can affect survival time.

In conclusion In this study, patients with prostate cancer had a poor 5-year survival rate. Screening of men for cancer diagnosis in early stages and applying the appropriate treatment option, it seems to improve survival of patients. Further studies are needed to monitor survival of patients with prostate cancer in Iran.

\section{References}

1. Pakzad R, Mohammadian-Hafshejani A, Ghoncheh M, Pakzad I, Salehiniya H. The incidence and mortality of prostate cancer and its relationship with development in Asia. Prostate international. 2015;3(4):135-40.

2. Siegel RL, Miller KD, Jemal A. Cancer statistics, 2016. CA: a cancer journal for clinicians. 2016;66(1):7-30.

3. Zeinab Fazeli MAP, Mohsen Vahedi, Alireza Abadi, Sepideh Gholiizadeh, Mohammad Reza Zali. Mortality rate of prostate cancer in iranian men. International Journal of Analytical, Pharmaceutical and Biomedical Sciences. 2015;4(5):70-5.

4. Farmer R. Prostate cancer: epidemiology and risk factors. Trends in Urology \& Men's Health. 2008;13(3):32-4.

5. Pakzad R, Rafiemanesh H, Ghoncheh M, Sarmad A, Salehiniya H, Hosseini S, et al. Prostate Cancer in Iran: Trends in Incidence and Morphological and Epidemiological
Characteristics. Asian Pacific journal of cancer prevention : APJCP. 2016;17(2):839-43.

6. Zahir ST, Nazemian MR, Zand S, Zare S. Survival of patients with prostate cancer in Yazd, Iran. Asian Pacific journal of cancer prevention : APJCP. 2014;15(2):883-6.

7. Ang M, Rajcic B, Foreman D, Moretti K, O'Callaghan ME. Men presenting with prostate-specific antigen (PSA) values of over $100 \mathrm{ng} / \mathrm{mL}$. BJU international. 2016;117 Suppl 4:68-75.

8. Aarts MJ, Koldewijn EL, Poortmans PM, Coebergh JW, Louwman M. The impact of socioeconomic status on prostate cancer treatment and survival in the southern Netherlands. Urology. 2013;81(3):593-9.

9. Holmberg L, Robinson D, Sandin F, Bray F, Linklater KM, Klint A, et al. A comparison of prostate cancer survival in England, Norway and Sweden: a population-based study. Cancer epidemiology. 2012;36(1):e7-12.

10. Shafique K, Morrison DS. Socio-economic inequalities in survival of patients with prostate cancer: role of age and Gleason grade at diagnosis. PloS one. 2013;8(2):e56184.

11. Baade PD, Youlden DR, Coory MD, Gardiner RA, Chambers SK. Urban-rural differences in prostate cancer outcomes in Australia: what has changed? The Medical journal of Australia. 2011;194(6):293-6.

12. Smailyte G, Kurtinaitis J. Cancer mortality differences among urban and rural residents in Lithuania. BMC public health. 2008;8:56.

13. Yu XQ, Luo Q, Smith DP, O'Connell DL, Baade PD. Geographic variation in prostate cancer survival in New South Wales. The Medical journal of Australia. 2014;200(10):586-90.

14. Maldonado E, Malouff TD, Marsh S, Silberstein PT. Impact of location on survival in prostate cancer. Journal of Clinical Oncology. 2016;34(15_suppl):e16590-e.

15. Bechis SK, Carroll PR, Cooperberg MR. Impact of age at diagnosis on prostate cancer treatment and survival. Journal of clinical oncology : official journal of the American Society of Clinical Oncology. 2011;29(2):235-41.

16. Baade PD, Youlden DR, Cramb SM, Dunn J, Gardiner RA. Epidemiology of prostate cancer in the Asia-Pacific region. Prostate international. 2013;1(2):47-58.

17. Mathers MJ, Roth S, Klinkhammer-Schalke M, Gerken M, Hofstaedter F, Wilm S, et al. Patients with localised prostate cancer ( $\mathrm{t} 1$ - $\mathrm{t} 2$ ) show improved overall long-term survival compared to the normal population. Journal of Cancer. 2011;2:76-80.

18. Studer UE, Hauri D, Hanselmann S, Chollet D, Leisinger HJ, Gasser T, et al. Immediate versus deferred hormonal treatment for patients with prostate cancer who are not suitable for curative local treatment: results of the randomized trial SAKK 08/88. Journal of clinical oncology : official journal of the American Society of Clinical Oncology. 2004;22(20):4109-18.

19. Wallis CJD, Saskin R, Choo R, Herschorn S, Kodama RT, Satkunasivam R, et al. Surgery Versus Radiotherapy for Clinically-localized Prostate Cancer: A Systematic Review and Meta-analysis. European urology. 2016;70(1):21-30.

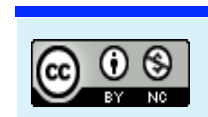

This work is licensed under a Creative Commons AttributionNon Commercial 4.0 International License. 